\title{
Clinical characteristics of critically ill cancer patients who are undergoing isolated limb perfusion
}

\author{
SILVIO A. ÑAMENDYS-SILVA ${ }^{1-3}$, ARTURO M. RUIZ-BELTRAN ${ }^{1}$, MIREYA BARRAGÁN-DESSAVRE ${ }^{1,3}$, \\ ANDORENI R. BAUTISTA-OCAMPO ${ }^{1}$, ABELARDO MENESES-GARCÍA ${ }^{1}$, \\ OCTAVIO GONZÁLEZ-CHON ${ }^{3}$ and ANGEL HERRERA-GÓMEZ ${ }^{1}$
}

\author{
${ }^{1}$ Department of Critical Care Medicine, Instituto Nacional de Cancerología, Mexico City $14080 ;{ }^{2}$ Department of Critical Care \\ Medicine, Instituto Nacional de Ciencias Médicas y Nutrición Salvador Zubirán, Mexico City 14080; \\ ${ }^{3}$ Department of Critical Care Medicine, Fundación Clínica Médica Sur, Mexico City 14050, Mexico
}

Received February 16, 2017; Accepted May 22, 2017

DOI: $10.3892 /$ mco.2017.1401

\begin{abstract}
The aim of the present study was to investigate the incidence of organ dysfunction, and to describe the clinical characteristics and intensive care unit (ICU) outcomes of critically ill cancer patients who were admitted to an oncological ICU during the isolated limb perfusion post-operative period. The present study was an observational investigation of 42 critically ill cancer patients who were admitted to the ICU of the Instituto Nacional de Cancerología, during the isolated limb perfusion post-operative period, between July 2010 and February 2016. The mean age of the patients was $45.7 \pm 16.9$ years, and $45.2 \%$ (19 cases) were female. Soft tissue sarcoma was the most common pre-operative diagnosis (38.1\%), and the mean duration of surgery was $267.6 \pm 50.1$ min. Furthermore, a mean blood loss volume of $732.3 \pm 526.1$ $\mathrm{ml}$ during the procedure was recorded, and the patients received a mean volume of $3.88 \pm 1.281$ crystalloid fluid during the surgical procedure, subsequently requiring an additional $2.95 \pm 6.281$ on the first post-operative day. The incidence of organ dysfunction was $90.5 \%$ and was most frequently noted in the respiratory (81\%), hepatic (33\%), hematologic (31\%) and renal $(11.9 \%)$ systems. No patients succumbed to the disease during the ICU and hospital stay. Nevertheless, $<10 \%$ of the patients required vasopressors. Additionally, $<5 \%$ of the patients required invasive mechanical ventilation. Therefore, ICU admission directly following isolated limb perfusion should not be standardized.
\end{abstract}

Correspondence to: Dr Silvio A. Namendys-Silva, Department of Critical Care Medicine, Instituto Nacional de Cancerología, San Fernando Avenue No. 22, Col. Sección XVI, Delegación Tlalpan, Mexico City 14080, Mexico

E-mail: snamendys@incan.edu.mx

Key words: critically ill cancer patients, isolated limb perfusion, critical care, intensive care, tumor necrosis factor $\alpha$, melphalan

\section{Introduction}

Since it was introduced in 1957, isolated limb perfusion has been an available therapeutic option for patients with locally advanced neoplasia, such as melanoma and sarcoma $(1,2)$. Isolation of the affected limb allows for the administration of high doses of chemotherapeutic agents, eliminating their associated severe systemic effects $(1,2)$. For this procedure, an extracorporeal circulation circuit is employed that incorporates a pump and an oxygenator to warm the perfusion solution and to enhance oxygen pressure prior to its administration (3). Melphalan and tumor necrosis factor $\alpha(\mathrm{TNF} \alpha)$, used either alone or in combination, are the cytotoxic agents of choice, and can be administered at doses $\geq 15-20$ times the doses that are tolerated after systemic administration (4). A potential hazard that can occur during the procedure is the leaking of these agents into the systemic circulation (5). Nevertheless, the most common frequent adverse effects present locally, and consist of edema, erythema and unusual cases of neuropathy and vascular complications (5).

$\mathrm{TNF} \alpha$ is a pleiotropic cytokine that is capable of destroying tumor neoangiogenic vessels $(6,7)$. Nevertheless, it is also involved in sepsis-induced cardiovascular dysfunction $(6,7)$. Systemic toxicity appears to be associated with the amount of leakage of these cytotoxic agents into the systemic circulation, and it is recommended that the procedure be stopped when this amount exceeds $10 \%$ (8). When it appears, systemic toxicity is usually limited, consisting of nausea and post-operative emesis, as well as transitory myelosuppression (4). However, due to the potential toxicity of these treatments, patients are often subject to invasive hemodynamic monitoring (4).

The aim of the present study was to investigate the incidence of organ dysfunction, and to describe the clinical characteristics and intensive care unit (ICU) outcomes of critically ill cancer patients who were admitted to an oncological ICU during the period following surgical isolated limb perfusion.

\section{Patients and methods}

The present study was an observational and qualitative investigation of 42 critically ill cancer patients who were admitted 
to the ICU of the Instituto Nacional de Cancerología. All consecutive who were admitted to the ICU during the isolated limb perfusion post-operative period were included, between July 2010 and February 2016.

The chemotherapeutic agents used included TNF $\alpha$ and melphalan. Demographical, clinical and pathological data were collected from each patient on the first day following ICU admission, including the following: Location of the primary tumor; comorbidity; surgical duration; perioperative bleeding volume; crystalloid fluid volume required during the surgical procedure. In addition, during the initial $24 \mathrm{~h}$ of ICU admission, the following data were recorded: Complications (medical and surgical); mechanical ventilation and vasopressor therapy requirements and duration periods; ICU and hospital length of stay; ICU and hospital mortality rates due to any cause. Organ dysfunction was defined according to the Mexican Sequential Organ Failure Assessment (MEXSOFA) score as $\geq 1$ point for any organ system (9).

Additionally, the Acute Physiology and Chronic Health Evaluation II and MEXSOFA scores were calculated using the poorest acute physiological variable values obtained during the first $24 \mathrm{~h}$ of ICU admission (10). Systemic inflammatory response syndrome was defined as two or more of the following: i) Temperature $>38^{\circ} \mathrm{C}$ or $<36^{\circ} \mathrm{C}$; ii) heart rate $>90 / \mathrm{min}$; iii) respiratory rate $>20 / \mathrm{min}$ or $\mathrm{PaCO}_{2}<32 \mathrm{~mm} \mathrm{Hg}(4.3 \mathrm{kPa})$; iv) white blood cell count $>12,000 / \mathrm{mm}^{3}$ or $<4,000 / \mathrm{mm}^{3}$ or $>10 \%$ immature bands (11). Subsequently, the patients were divided into two groups according to the number of organ system dysfunctions ( $\leq 1$ organ dysfunction, $n=21 ; \geq 2$ organ dysfunctions, $n=21$ ). The patients were followed-up for one year after discharge from the ICU. Patients were considered lost to follow-up if they had not visited the hospital for 90 days. The Bioethics Committee of The Instituto Nacional de Cancerología approved the present study, and the requirement to obtain informed consent was waived.

Statistical analysis. Categorical data are expressed as percentages. Continuous variables are expressed as the mean \pm standard deviation. All continuous variables were analyzed for normality using the Kolmogorov-Smirnoff test and compared by performing a Student's t-test. All statistical analyses were performed using SPSS version 22.0 (IBM Corp., Armonk, NY, USA). Two-sided $\mathrm{P}<0.05$ values were considered to indicate a statistically significant difference.

\section{Results}

The mean age of the patients was $45.7 \pm 16.9$ years, and $45.2 \%$ (19 cases) were female. Soft tissue sarcoma was the most common pre-operative diagnosis $(38.1 \%)$, and the mean duration of surgery was $267.6 \pm 50.1 \mathrm{~min}$. Furthermore, a mean blood loss volume of $732.3 \pm 526.1 \mathrm{ml}$ was recorded during the procedure; the patients received a mean peri-operative volume of 3.88 \pm 1.28 liters crystalloid fluid and required an additional $2.95 \pm 6.28$ liters on the first post-operative day (Table I).

During the initial $24 \mathrm{~h}$ following admission to the ICU, four patients required vasopressors $(9.5 \%)$ and two patients required invasive mechanical ventilation $(4.7 \%)$ for a mean duration of one day. Furthermore, $21.4 \%$ of the patients exhibited systemic inflammatory response syndrome.
Table I. Patient demographic and clinical data

\begin{tabular}{|c|c|}
\hline Characteristics & Values \\
\hline Total patients, n (\%) & $42(100)$ \\
\hline Age, years ${ }^{\mathrm{a}}$ & $45.7 \pm 16.9$ \\
\hline \multicolumn{2}{|l|}{ Sex, n $(\%)$} \\
\hline Female & $19(45.2)$ \\
\hline Male & $23(54.8)$ \\
\hline APACHE II score ${ }^{\mathrm{a}}$ & $9.1 \pm 3.3$ \\
\hline MEXSOFA score ${ }^{b}$ & $3(2-4)$ \\
\hline \multicolumn{2}{|l|}{ Diagnosis, n (\%) } \\
\hline Sarcoma & $16(38.1)$ \\
\hline Liposarcoma & $8(19)$ \\
\hline Melanoma & $7(16.7)$ \\
\hline Fibromatosis & $5(11.9)$ \\
\hline Squamous cell carcinoma & $2(4.8)$ \\
\hline Neurogenic sarcoma & $1(2.4)$ \\
\hline Myxofibrosarcoma & $1(2.4)$ \\
\hline Fibroblastoma & $1(2.4)$ \\
\hline Merkel cell carcinoma & $1(2.4)$ \\
\hline Duration of surgery, $\min ^{\mathrm{a}}$ & $267.6 \pm 50.1$ \\
\hline $\mathrm{TNF} \alpha$ administration, $\mathrm{n}(\%)$ & $37(88)$ \\
\hline Perioperative bleeding, $\mathrm{ml}^{\mathrm{a}}$ & $732.3 \pm 526.1$ \\
\hline Vasopressors, n (\%) & $4(9.5)$ \\
\hline Invasive mechanical ventilation, n (\%) & $2(4.7)$ \\
\hline \multicolumn{2}{|l|}{ Crystalloid fluid received, liters ${ }^{\mathrm{a}}$} \\
\hline During surgery & $3.88 \pm 1.28$ \\
\hline Following admission to the ICU & $2.95 \pm 6.28$ \\
\hline Length of stay in the ICU, days ${ }^{\mathrm{a}}$ & $1(0-1)$ \\
\hline
\end{tabular}

${ }^{\text {aD }}$ ata are presented as the mean \pm standard deviation. ${ }^{\text {bData }}$ are presented as the median (interquartile range). APACHE, acute physiology and chronic health evaluation; MEXSOFA, Mexican sequential organ failure assessment; $\mathrm{TNF} \alpha$, tumor necrosis factor $\alpha$; ICU, intensive care unit.

Overall, 23 patients (54\%) required packed red blood cell transfusions. Additionally, the incidence of organ dysfunction was $90.5 \%$ and was most frequently noted in the respiratory $(81 \%)$, hepatic $(33 \%)$, hematologic $(31 \%)$ and renal $(11.9 \%)$ systems (Table II). Five of the patients (11.9\%) exhibited renal dysfunction; however, no patients required or received renal replacement therapy. During the ICU and hospital stay, no patients were recorded as having succumbed to the disease. After one year of follow-up, all patients remained alive. In total, $4.7 \%$ of patients (2/42) were lost to follow-up, according to the aforementioned criterion.

\section{Discussion}

Isolated limb perfusion using $\mathrm{TNF} \alpha$ has previously been associated with major systemic changes that are characterized by a septic-like shock syndrome $(12,13)$. In the current study, the incidence of organ dysfunction was $90.5 \%$ in critically ill cancer patients who were admitted to the ICU during the 
Table II. Patients according to the number of dysfunctional organ systems.

\begin{tabular}{|c|c|c|c|}
\hline \multirow[b]{2}{*}{ Variables } & \multicolumn{2}{|c|}{ Organ dysfunction } & \multirow[b]{2}{*}{ P-value } \\
\hline & $\leq 1(n=21)$ & $\geq 2(\mathrm{n}=21)$ & \\
\hline Hemoglobin, $\mathrm{g} / \mathrm{l}^{\mathrm{a}}$ & $10.39 \pm 1.4$ & $10.07 \pm 1.67$ & 0.513 \\
\hline Platelets, $\times 10^{9} / \mathrm{l}^{\mathrm{b}}$ & $189(174-233)$ & $138(120-157)$ & $<0.001^{\mathrm{c}}$ \\
\hline White blood cells, $\times 10^{9} / 1^{\mathrm{a}}$ & $17.9 \pm 5.9$ & $17.1 \pm 4.3$ & 0.735 \\
\hline Creatinine, $\mathrm{mg} / \mathrm{dl}^{\mathrm{b}}$ & $0.65(0.61-0.84)$ & $0.78(0.63-0.99)$ & 0.217 \\
\hline Albumin, $\mathrm{mg} / \mathrm{dl}^{\mathrm{a}}$ & $2.49 \pm 0.39$ & $2.49 \pm 0.65$ & 0.980 \\
\hline Total bilirubin, $\mathrm{mg} / \mathrm{dl}^{\mathrm{b}}$ & $0.9(0.7-1.2)$ & $1.2(1.0-1.7)$ & $0.032^{\mathrm{c}}$ \\
\hline $\mathrm{pH}^{\mathrm{b}}$ & $7.31(7.30-7.37)$ & $7.32(7.30-7.37)$ & 0.800 \\
\hline Bicarbonate, $\mathrm{mEq} / \mathrm{l}^{\mathrm{b}}$ & $19.7(18.0-22.1)$ & $20.0(19.0-21)$ & 0.504 \\
\hline Lactate, $\mathrm{mmol} / \mathrm{l}^{\mathrm{b}}$ & $2.4(2.18-3.2)$ & $2.4(1.3-2-6)$ & 0.231 \\
\hline Sodium, mEq/1 ${ }^{\mathrm{a}}$ & $137.4 \pm 2.39$ & $138.3 \pm 2.7$ & 0.264 \\
\hline Potassium, mEq/1 ${ }^{\mathrm{b}}$ & $3.9(3.7-4.0)$ & $3.8(3.6-4.2)$ & 0.604 \\
\hline Chloride, $\mathrm{mEq} / \mathrm{l}^{\mathrm{a}}$ & $110.4 \pm 3.8$ & $112.3 \pm 3.8$ & 0.129 \\
\hline Calcium, mg/da ${ }^{\mathrm{a}}$ & $7.31 \pm 0.49$ & $6.85 \pm 1.58$ & 0.307 \\
\hline Phosphorus, mg/dl ${ }^{b}$ & $3.3(3.1-3.6)$ & $3.1(2.8-3.9)$ & 0.571 \\
\hline Magnesium, mEq/1 $\mathrm{l}^{\mathrm{a}}$ & $1.62 \pm 0.46$ & $1.59 \pm 0.28$ & 0.828 \\
\hline
\end{tabular}

${ }^{a}$ Data presented as the mean \pm standard deviation. ${ }^{b}$ Data presented as the median (interquartile range). ${ }^{c} \mathrm{P}<0.05$. ICU, intensive care unit.

isolated limb perfusion post-operative period, being most frequently noted in the respiratory, hepatic and coagulation systems.

Laurenzi et al (14) reported that $17 \%$ of observed critically ill patients developed severe respiratory and cardiovascular toxicity; of these patients, all required mechanical ventilation and $11 \%$ required vasoactive treatment (14). In the present study, $<10 \%$ of the patients required vasopressors and $<5 \%$ required invasive mechanical ventilation. All patients were extubated during the first day on the ICU.

In contrast to prior studies, the current study did not report the volume of drug leakage from the limb to the systemic circulation, which is reportedly correlated with the degree of systemic toxicity $(8,15)$. It is notable that isolated limb perfusion is stopped when the leakage from the limb to the systemic circulation reaches $5 \%$ when using TNF $\alpha$, or $10 \%$ when using melphalan in the Instituto Nacional de Cancerología.

The primary limitations of the present study were that it represented the experience of a single oncological ICU and that the sample size was small.

In conclusion, a high incidence of organ dysfunction was observed. Nevertheless, $<5 \%$ of the patients required invasive mechanical ventilation and $<10 \%$ required vasopressors Therefore, ICU admission directly following isolated limb perfusion should not be standardized.

\section{Acknowledgements}

The present authors thank the ICU nurses and medical staff of the Instituto Nacional de Cancerología who were involved in the care of the study patients. The present study was supported by institutional funds.

\section{References}

1. Smith HG, Cartwright J, Wilkinson MJ, Strauss DC, Thomas JM and Hayes AJ: Isolated Limb Perfusion with Melphalan and Tumour Necrosis Factor $\alpha$ for In-Transit Melanoma and Soft Tissue Sarcoma. Ann Surg Oncol 22 (Suppl 3): S356-S361, 2015.

2. Nieweg $\mathrm{OE}$ and Kroon BB: Isolated limb perfusion with melphalan for melanoma. J Surg Oncol 109: 332-337, 2014.

3. Ruschulte H, Shi S, Tseng WW, Kolodzie K, Crawford PC, Schneider DB, Kashani-Sabet M, Minor D, Apfel C and Leong SP: Anesthesia management of patients undergoing hyperthermic isolated limb perfusion with melphalan for melanoma treatment: An analysis of 17 cases. BMC Anesthesiol 13: 15, 2013.

4. Bhangu A, Broom L, Nepogodiev D, Gourevitch D and Desai A: Outcomes of isolated limb perfusion in the treatment of extremity soft tissue sarcoma: A systematic review. Eur J Surg Oncol 39: 311-319, 2013.

5. Vrouenraets BC, Kroon BB, Ogilvie AC, van Geel AN, Nieweg OE, Swaak AJ and Eggermont AM: Absence of severe systemic toxicity after leakage-controlled isolated limb perfusion with tumor necrosis factor- $\alpha$ and melphalan. Ann Surg Oncol 6: 405-412, 1999.

6. Saíd HM, Gómez AH, Ponce JLA and Jaime G: Perfusión Aislada de Extremidad. Una Alternativa a la Amputación en Tumores Avanzados por Melanoma, Sarcomas y Otros Tumores Irresecables de las Extremidades. Med Sr 9: 148-155, 2002.

7. Eggimann P, Chioléro R, Chassot PG, Lienard D, Gerain J and Lejeune F: Systemic and hemodynamic effects of recombinant tumor necrosis factor alpha in isolation perfusion of the limbs. Chest 107: 1074-1082, 1995.

8. Paulsen IF, Chakera AH, Schmidt G, Drejøe J, Klyver H, Oturai PS, Hesse B, Drzewiecki K and Mortensen J: Radionuclide leakage monitoring during hyperthermic isolated limb perfusion for treatment of local melanoma metastasis in an extremity. Clin Physiol Funct Imaging 35: 301-305, 2015.

9. Ñamendys-Silva SA, Silva-Medina MA, Vásquez-Barahona GM, Baltazar-Torres JA, Rivero-Sigarroa E, Fonseca-Lazcano JA and Domínguez-Cherit G: Application of a modified sequential organ failure assessment score to critically ill patients. Braz J Med Biol Res 46: 186-193, 2013.

10. Knaus WA, Draper EA, Wagner DP, Zimmerman JE and Apache II: APACHE II: A severity of disease classification system. Crit Care Med 13: 818-829, 1985. 
11. Bone RC, Balk RA, Cerra FB, et al; American College of Chest Physicians/Society of Critical Care Medicine Consensus Conference: definitions for sepsis and organ failure and guidelines for the use of innovative therapies in sepsis. Crit Care Med 20:864-874, 1992.

12. Lienard D, Ewalenko P, Delmotte JJ, Renard N and Lejeune FJ: High-dose recombinant tumor necrosis factor alpha in combination with interferon gamma and melphalan in isolation perfusion of the limbs for melanoma and sarcoma. J Clin Oncol 10: 52-60, 1992.

13. Vaglini M, Belli F, Ammatuna M, Inglese MG, Manzi R, Prada A Persiani L, Santinami M, Santoro N and Cascinelli N: Treatment of primary or relapsing limb cancer by isolation perfusion with high-dose alpha-tumor necrosis factor, gamma-interferon, and melphalan. Cancer 73: 483-492, 1994.
14. Laurenzi L, Natoli S, Di Filippo F, Calamaro A, Centulio F, Anzà M, Cavaliere F, Marcelli ME, Garinei R and Arcuri E: Systemic and haemodynamic toxicity after isolated limb perfusion (ILP) with TNF- $\alpha$. J Exp Clin Cancer Res 23: 225-231, 2004.

15. Christoforidis D, Chassot PG, Mosimann F, Lienard D, Brunstein F, Bejko D, Lejeune FJ and Chiolero R: Isolated limb perfusion: Distinct tourniquet and tumor necrosis factor effects on the early hemodynamic response. Arch Surg 138: 17-25, 2003. 